\title{
PROCESOS DE TRANSICIÓN EN LA MATERNIDAD Y PATERNIDAD ADOPTIVA INTERNACIONAL
}

\author{
PROCESSES OF TRANSITION IN THE INTERNATIONAL ADOPTIVE \\ MOTHERHOOD AND FATHERHOOD
}

\author{
Diana Jareño Ruiz \\ Universidad de Alicante. Alicante/España \\ diana.jareno@ua.es
}

Recibido/Received: $31 / 07 / 2018$

Modificado/Modified: 14/08/2018

Aceptado/Accepted: 22/09/2018

\section{RESUMEN}

La filiación adoptiva internacional en España adquiere relevancia numérica y visibilidad social a partir de la última década del siglo XX. Es en este momento cuando se puede identificar un modelo moderno de adopción, caracterizado por la diversidad de formas familiares, la capacidad de elección de sus miembros y su aceptación social. El objetivo de esta contribución es analizar los procesos de transición a la paternidad y maternidad adoptiva atendiendo al tipo de familia y sexo de los adoptantes. Se busca identificar los elementos de las dinámicas intrafamiliares que determinan las relaciones entre los integrantes de las familias adoptivas, y descubrir si ellas siguen patrones de continuidad o de cambio respecto a sus familias de orientación o a otros modelos familiares. Para ello se utilizan relatos de vida cruzados, que aportan una visión contrastada del fenómeno, recogiendo trayectorias biográficas diferenciadas por género.

\section{PALABRAS CLAVE}

Adopción internacional; maternidad/paternidad; dinámicas intrafamiliares; roles de género; relaciones de poder.

\section{SUMARIO}

1. Introducción. 2. Metodología y técnica de investigación. 3. Análisis empírico de resultados. 3.1. El contexto social en los procesos de transición a la maternidad y paternidad adoptiva. 3.2. Presencia por sexos en la esfera pública y la esfera privada. 4. Conclusiones. Bibliografía.

\footnotetext{
ABSTRACT

International adoption and filiation in Spain acquires numerical relevance and social visibility since the last decade of the twentieth century. It is now when a modern adoption model can be identified, characterized by the diversity of family forms, the capacity of choice of its members and its social acceptance. The aim of this contribution is to analyze the processes of transition to adoptive motherhood and fatherhood and by type of family and sex of the adoptive parents. It seeks to identify the elements of the dynamics within the family that determine the relationships among the members of adoptive families, and discover whether they follow patterns of continuity or change from their families counseling or other family models. For this purpose, cross-referenced life stories are used, which
} 
provide a contrasted vision of the phenomenon, collecting biographical trajectories differentiated by gender.

\section{KEYWORDS}

International Adoption; Motherhood; Fatherhood; Dynamics within the Family; Gender Roles; Power Relations.

\section{CONTENTS}

1. Introduction. 2. Methodology and research techniques. 3. Empirical results. 3.1. The social context in the processes of transition to adoptive motherhood and fatherhood. 3.2. Presence by sexes in the public sphere and the private sphere. 4. Conclusions. References.

\section{INTRODUCCIÓN}

La familia en España se encuentra inmersa en un profundo proceso de transformación. Ésta, a su vez, no es más que la respuesta a los cambios sociales y nuevos estilos de vida que operan en los países occidentales. En el resto de Europa, estos cambios comenzaron a hacerse visibles en las décadas de los setenta y ochenta, mientras que en el caso español este proceso se ha producido con retraso, pero caracterizado por una celeridad ya vivida en otros procesos de cambio socio-demográficos.

El cambio en las familias se manifiesta en la diversidad de formas familiares, como en sus formas de entrada, permanencia o salida de las mismas. Estos cambios han sido etiquetados de distintas maneras según la disciplina que los abordara: "Individualización" (Beck y Beck, 2003), "Segunda transición demográfica" (Van de Kaa, 1987; Lesthaeghe, 1995) o "Postmodernización de la cultura familiar" (Meil, 1999), son algunos de los términos y marcos teóricos aplicados. Sin lugar a dudas, el nexo entre las reflexiones apuntadas es la pérdida de control social, y con ello la ganancia de autonomía personal, sobre la configuración de los proyectos de vida de las personas. La emergencia de valores postmodernos en la sociedad española ha incidido en la estructura, formación y funcionamiento de las familias en las que los vínculos consanguíneos pierden importancia en favor de la elección personal. La postmodernización de la cultura familiar es la característica inequívoca del periodo en el que las adopciones internacionales empiezan a tener relevancia numérica en nuestro país. La institución de la adopción adquiere un relevante matiz: la adopción deja de ser una ficción de una paternidad biológica vivida en secreto, que buscaba proteger tanto a los padres adoptivos como a los biológicos, para ser un recurso legal para la constitución de una filiación igualmente válida que la alternativa biológica. Se pasa de un modelo tradicional de adopción a un modelo moderno, cuya consecuencia es su visibilidad como resultado de la mayor tolerancia y sensibilización social con este modelo familiar.

En España no será hasta los años noventa del siglo XX cuando esta opción de filiación adquiera protagonismo. Desde entonces, la tendencia dibujada por el flujo de adopciones internacionales no dejaba de crecer, alcanzando en 2004, con 5.541 adopciones en el extranjero, su posición como segundo país del mundo -después de EEUU- en constitución de adopciones internacionales (Selman, 2012; 2006). Los últimos datos proporcionados por las diferentes fuentes, mantienen a nuestro país en esta segunda posición, teniendo constituidas 54.261 adopciones internacionales (INE, 2016).

El año 2004 supone un punto de inflexión en la tendencia del flujo de adopciones internacionales en España. Desde entonces, estas han ido descendiendo de forma paulatina al 
igual que ha ocurrido en el resto de países receptores de menores adoptados en el extranjero. A pesar de la reducción del flujo de adopciones internacionales, la adopción ofrece interesantes retos para la reflexión y el avance en la sociología de la familia (RodríguezJaume y Jareño-Ruiz, 2015), porque proporciona una oportunidad única para abordar rutas no tradicionales en la constitución de unidades familiares reivindicando para el catálogo de 'nuevos tipos familiares' aquellas que desafían al modelo normativo y 'naturalizado' de la familia biológica.

Esta contribución describe los perfiles de las familias adoptivas internacionales de la provincia de Alicante e indaga sobre las razones de su existencia no solo como promotoras de la filiación social sino también como las causantes de la creación de unidades familiares con una identidad determinada. Las familias adoptivas, son por tanto causa y consecuencia de los cambios producidos en la cultura familiar española y, por tanto, en sus dinámicas internas.

El objetivo de este trabajo es analizar los procesos de transición a la paternidad y maternidad adoptiva atendiendo al tipo de familia y sexo de los adoptantes. Se busca delimitar los factores que convierten a la maternidad y paternidad adoptiva en nuevas formas de maternidad y paternidad, por lo que se requiere definir los elementos de las dinámicas intrafamiliares que determinan la base de las relaciones padre, madre e hijos o hijas en las familias adoptivas: estilos educativos, estrategias de construcción de identidad como padres y madres adoptivos y el reparto de roles y relaciones de poder en sus hogares.

\section{METODOLOGÍA Y TÉCNICA DE INVESTIGACIÓN}

La investigación utiliza la metodología cualitativa para el estudio sociológico de los procesos de transición a la maternidad y paternidad adoptiva de familias españolas que han adoptado menores en el extranjero. Interesa conocer y analizar el discurso de padres y madres, las motivaciones para constituir una filiación social y las vivencias de su paternidad y maternidad en el interior de una familia adoptiva. La estrategia elegida será la biográfica, también denominada "método biográfico" por Denzin en su monografia Interpretetive Biography (1989). Desde esta perspectiva, lo que interesa es conocer la visión que las familias adoptivas tienen de sus procesos de transición a la paternidad y maternidad, y no tanto la veracidad del relato.

La técnica de investigación escogida son los relatos de vida, utilizándolos en el análisis como relatos paralelos, comparación entre las diferentes familias, y relatos cruzados, al comparar los discursos de los dos miembros de la pareja en los casos de familias biparentales. Por tanto, la historia está explicada por varias voces que se corresponden con padres o madres para descubrir las similitudes o diferencias en los discursos. Dicha técnica busca los elementos subjetivos de la experiencia social (Valles, 1997) para describir, no solo los casos individuales, sino el caso de un grupo (las familias adoptivas) y de un fenómeno social (la adopción internacional).

El guion utilizado en esta investigación con padres y madres de menores adoptados internacionalmente ha sido elaborado atendiendo a cuatro bloques temáticos principales: (a) preguntas introductorias -información personal, familia de orientación, entorno y amistades-; (b) sociología de la familia -estructura y morfología familiar, alianza, motivaciones, maternidad y paternidad, roles y poder-; (c) sociología de la infancia -valor del niño, crianza-; y, (d) sociología de las adopciones -proceso de adopción internacional, satisfacción y felicidad-. 
La elección de las familias que han constituido una adopción internacional para realizar los relatos de vida, se ha realizado siguiendo el criterio de heterogeneidad. Para aportar esta heterogeneidad se ha recurrido a un muestreo intencional (Patton, 1990) a partir de diferentes formas familiares y distintas composiciones de hogares (biparentales/monoparentales, filiación adoptiva/filiación mixta, país de origen de la persona adoptada). De este modo, la muestra está compuesta por un total de cuarenta personas que se distribuyen en veinticuatro familias, que se derivan del trabajo de campo realizado en la tesis doctoral Familias en transición: estudio sociológico de las familias adoptivas internacionales en la provincia de Alicante (Jareño-Ruiz, 2014).

\section{ANÁLISIS EMPÍRICO DE RESULTADOS}

La elección se ha convertido en el nuevo elemento de las reglas de parentesco. La filiación adoptiva es elección y no solo una ficción social de un auténtico vínculo de parentesco. Este es el motivo por el que las familias adoptivas se consideran un desafío para la morfología familiar y las relaciones basadas en la consanguinidad ya que transgreden los fundamentos básicos de la ideología familiar. Las familias adoptivas, pueden ser denominadas como "familias que elegimos", concepto que Kath Weston (2003) aplicó a las familias de gays y lesbianas. Siguiendo su argumentación, las personas utilizan el parentesco para pensar y actuar en su entorno social. Los cambios producidos en el parentesco no solo influyen a nivel macrosocial sino que alcanzan a las diferentes escenas de la vida cotidiana a través del cuestionamiento de posiciones tradicionalistas y la apuesta por nuevas concepciones ideológicas.

El uso de relatos de vida cruzados recoge trayectorias biográficas diferenciadas por tipo de familia y género. En este caso se comparan los relatos de las veintiuna familias biparentales, que son narran un fragmento de la vida compartida.

\subsection{El contexto social en los procesos de transición a la maternidad y paternidad adoptiva}

La decisión de convertirse en madres y padres adoptivos es fruto de una reflexión personal y de pareja, pero también de otros condicionantes individuales y sociales. La construcción de la maternidad y la paternidad adoptiva se fundamenta en la relación con su contexto social. Los procesos de socialización y construcción de identidad tienen a la familia de orientación de los adoptantes como principal agente influyente.

Las cuarenta personas que ofrecen sus relatos, y que en el momento de realizar la narración sobre su biografía ya habían compuesto su propia familia, pertenecieron a una familia de orientación junto a sus padres y hermanos. La dinámica familiar que se desarrollaba en cada hogar les proporciona un modelo que reproducir o rechazar en la distribución de roles y poder de sus nuevas familias, las familias adoptivas. Los roles de padre y madre son los que se someten a revisión y, junto a ellos, los mitos sociales sobre la biología y el género.

Las personas que colaboraron en el estudio nacieron entre el año 1956 y el 1981. La mayoría de ellas, treinta y dos de los cuarenta casos, nacieron antes de 1975. El ideal de familia de la época en España delimitaba las funciones en el interior y el exterior de la familia a partir de los papeles que debían desempeñar el conjunto de sus miembros. Las mujeres estaban destinadas a la esfera privada, donde se encargaban del cuidado y los afectos; en algunos de los casos sus funciones se ampliaban a actividades de apoyo en 
negocios familiares y a la administración de la economía doméstica. El hombre, situado en la esfera pública, encargado de abastecer económicamente al hogar, se erigía como el varón proveedor y ostentaba la figura de autoridad en la casa.

Como cualquier ideal, este modelo de familia contrastaba en sendas ocasiones con la realidad de muchos hogares españoles. En el caso de este estudio, de las cuarenta familias de orientación analizadas, diecisiete de ellas seguían este patrón en el que la mujer trabajaba en la casa y se hacía cargo del cuidado de la descendencia. Ocho de las familias se distanciaban de esta división de las esferas pública y privada por sexo, trabajando remuneradamente ambos miembros de la pareja fuera del hogar; seis de las ocho familias se corresponden con las familias de orientación más jóvenes del estudio, siendo cuatro de ellas las que tuvieron a sus hijos e hijas en los primeros años de la transición española. En el resto de casos, quince de los cuarenta, además del trabajo remunerado del hombre también entraba un salario por parte de su mujer durante una determinada época del ciclo familiar. De estas quince mujeres, hay cuatro sobre las que no se tienen referencias temporales, tres trabajaron antes de tener a los niños y niñas, otras tres cuando sus hijos e hijas habían crecido y las últimas cinco mujeres realizaron su trabajo remunerado en su propia casa, práctica habitual en la zona levantina por su actividad en el sector del calzado.

El guion de los relatos incluía una pregunta sobre la percepción que las madres de las y los adoptantes tenían sobre el trabajo fuera del hogar. En aquel contexto, en el que el trabajo remunerado de una mujer no era la norma, las valoraciones que las propias mujeres le otorgan, define la apertura hacia la generación que con posterioridad vivirían sus hijas e hijos. Nueve de los relatos confiesan desconocer la valoración que sus madres tenían respecto al trabajo ajeno a las tareas domésticas y de cuidado. De los relatos restantes (treinta y uno), diez de ellos afirman que a sus madres les hubiera gustado realizar dicha actividad pero que no tuvieron la oportunidad; nueve de ellos narran que para sus progenitoras el trabajo que desempeñaban era muy importante y lo valoraban positivamente; mientras que los otros doce consideran que a sus madres no les hubiera gustado trabajar. De estos últimos doce relatos, ocho mujeres no habían trabajado nunca y cinco de ellas sí lo habían hecho, exclusivamente por motivos de necesidad en el hogar.

Mi padre era albañil y mi madre en el zapato. Mi madre se dejó, bueno luego empezó a trabajar en casa cuando nació la pequeña. Cuando nació la pequeña entonces empezó a trabajar en casa pero siempre ha estado trabajando en el zapato y, normalmente, casi siempre fuera.

[Entrevistadora: ¿Decía que era importante para ella el trabajo?] No, si ella lo hubiese hecho como con mi hermana, si hubiese podido con lo que trabajaba en casa sacarnos adelante lo hubiese hecho así. Lo que pasa es que no le quedaba otro remedio que salir fuera (Madre familia 8, biparental, Etiopía, niños adoptados en 2008)

Padres y madres desempeñaban socialmente en la familia la figura autoritaria y la figura afectuosa respectivamente. Pero las vivencias de los adoptantes no siempre identifican esta división en sus hogares. Solo cinco de los casos consideran que el afecto era una parcela exclusiva de la madre y que el poder en el hogar lo ostentaba su padre. Entre el resto de relatos se descubre el caso de una madre que, tras la ruptura con su pareja, se hace cargo en solitario de su hija (actual familia adoptiva monoparental); trece narraciones en las que las figuras de afecto y autoridad se diluyen entre sus progenitores recibiendo el mismo trato por parte de ambos; y por último, veintiún casos que señalan que al pasar más tiempo con la madre como consecuencia del horario laboral del padre, les atribuyen a ellas las tareas de cuidados y las muestras de afectos. 
En las familias de orientación no solo se establecían diferencias en la pareja por cuestión de sexo sino que esas distinciones se trasladaban al tratamiento de las madres y padres con sus hijos e hijas. En dieciséis de los cuarenta relatos se afirma que en sus hogares existió, o hubiera existido -en el caso de familias de hijos únicos o con grupo de hermanos del mismo sexo-, una diferencia de trato entre hijos e hijas. Las chicas fueron socializadas atendiendo al rol que les "correspondía" como mujeres, ocupándose de las tareas de limpieza de la casa, mientras que sus hermanos quedaban exentos de las mismas.

[Entrevistadora: $Y$, ¿crees que tu madre trataba igual a tu hermano que a ti?] No, en absoluto.

[Entrevistadora: Esas cosas se percibían ¿no?] No, no, no, yo siempre he tenido la sensación de que mi familia... Mi madre nos ha educado, es una mujer que tiene unos, pues unos planteamientos muy poco igualitarios ¿no? por educación, y yo he sentido que en mi casa había una educación machista. Yo solo tenía un hermano. Éramos prácticamente de la misma [edad], no tenía menos de un año más que yo, nos llevábamos apenas un año, y yo sí que lo notaba (Madre familia 3, biparental, Bolivia; niño adoptado en 2002).

En trece de los relatos no existen diferencias en el trato entre hijos e hijas, en otros cinco no pudo profundizarse en dicha reflexión, y en los seis casos restantes, las diferencias que se producían entre hermanos y hermanas era por cuestiones de edad, beneficiándose indistintamente el primogénito o el más pequeño de los menores.

[Entrevistadora: ¿Crees que os trataban de forma diferente a los chicos y a las chicas en casa?] No. En la mía, no. También es verdad que mi hermano es el nene pero no porque sea chico. Yo creo que porque fue el primero y... y se le ve el plumero con él pero no por nene, yo creo que es porque es el primero (Madre familia 11, biparental, Etiopía, niño adoptado en 2007)

[Entrevistadora: ¿Había trato diferente? ¿Te quejas por ser chica en casa?] Me quejo por ser la primera, ser la rebelde y que todos los demás ya tenían un pedazo hecho (Madre familia 13, biparental, Bolivia, niño adoptado en 2003).

Las familias adoptivas objeto de estudio tienen en sus orígenes las pautas a seguir en la construcción de su maternidad y paternidad. En base a la experiencia vital durante su infancia y juventud introducen elementos de continuidad o de cambio en sus familias respecto a las familias de orientación. Su ejercicio de la maternidad o paternidad toma nuevos caminos, avalados bien por información y formación específica sobre la adopción y otros métodos de crianza, o apoyados en los modelos familiares en los que crecieron.

Realmente de las que yo he sacado información, pero que no es que me la den, de mis padres. $O$ sea, yo estoy criando a mi hijo lo más parecido a como mis padres me han criado a mí porque me parece la forma más correcta o la que más se adapta a mi forma de verla (Madre familia 9, biparental, Etiopía, niño adoptado en 2009).

Hombre, yo a la hora de la crianza de mis hijos me he inspirado en lo mejor de mi madre, o en lo que a mí me ha gustado de mi madre. Algunas cosas de mi padre, más bien pocas, por desgracia, de mi suegra y de mi prima. Y luego, pues lo que he podido leer ¿no? Pero lo que más, lo que me ha gustado de ella, es lo que yo he intentado aplicar luego, aplicármelo a mí para aplicárselo a mis hijos (Madre familia 8, biparental, Etiopía, niños adoptados en 2008). 
Aquellos casos que buscan nuevos apoyos para el ejercicio de la crianza adoptiva recurren al contacto con otras familias que también han constituido sus relaciones de filiación mediante la adopción. Ante las peculiaridades propias de una maternidad o paternidad adoptiva (revelación, interracialidad, interculturalidad o adopción abierta), las propias familias ponen en práctica diferentes estrategias para mitigar su desconocimiento. Necesitan compartir sus sentimientos y experiencias con otras personas que también hayan recurrido a la adopción como alternativa de filiación. En ellas encuentran la empatía y la posibilidad de establecer relaciones que no consiguen en otros contextos ya que padres y madres son conscientes de las creencias acerca de la adopción en la sociedad. La importancia que los lazos de sangre tienen en la ideología del parentesco, en la ideología familiar y en el ejercicio de la maternidad y paternidad, obligan a las familias adoptivas a una constante defensa para mostrar una igualdad social que legislativamente ya está recogida. El reconocimiento o no de las diferencias en los discursos se adscribe a la "divulgación terapéutica" descrita por Miall (1989) como estrategia de neutralización del estigma de la adopción.

Dentro de estas estrategias se incluye la creación de asociaciones de familias adoptivas. Siguiendo la definición de Luis Ayuso (2007), las asociaciones familiares son ejemplos vanguardistas del cambio social, que ejemplifican el equilibrio entre las esferas pública y privada de la sociedad. Se constituyen como espacios en los que compartir inquietudes, buscar soluciones o reivindicar su reconocimiento ante el resto de actores sociales; su finalidad es la de ayudar en las dificultades y facilitarle el cumplimiento de sus funciones. Nueve de las veinticuatro familias han pertenecido a una asociación de familias adoptivas en algún momento desde que iniciaron el proceso de adopción; incluso en tres de los casos las madres ocupaban puestos importantes de responsabilidad dentro de las asociaciones. En el momento en el que se recogieron los relatos, eran cinco las familias que continuaban colaborando en sus actividades. La divulgación terapéutica se erige como el mayor apoyo, libre de prejuicios, que las familias adoptivas utilizan para afianzar su construcción familiar.

\subsection{Presencia por sexos en la esfera pública y la esfera privada}

La distribución de roles y el ejercicio de poder conforman el análisis de la dinámica de la vida familiar. Es necesario para ello contar con las veintiuna familias biparentales que componen este trabajo. La esfera pública y la esfera privada son las dos áreas en las que los miembros de una pareja desempeñan sus diferentes tareas y realizan su toma de decisiones como individuos y miembros de una familia.

La decisión de tener hijos e hijas responde a una "necesidad expresiva de las personas" (Cea D'Ancona, 2007: 111), pero no por ello se debe obviar que la llegada de los menores al hogar provoca conflictos de rol y pérdida de autonomía individual, que se añaden al coste económico que suponen. Será este el momento en el que el pacto conyugal adquiera su mayor relevancia para la organización de la vida familiar.

Los trabajas doméstico y asalariado son imprescindibles para el correcto funcionamiento de una familia. En ocho casos, hombres y mujeres trabajan fuera de casa lo que les proporciona un estatus y una compensación económica similar. En cinco familias donde ambos miembros de la pareja trabajan, la mujer tiene un trabajo inferior al del hombre en horario, cualificación y sueldo; en otra familia se da el caso contrario, siendo la mujer la que posee un mayor reconocimiento por su labor profesional. Mientras, en otras cinco familias las mujeres están dedicadas en exclusiva a las labores domésticas y de cuidado (tres por elección, una desempleada y otra por ser pensionista). En las dos familias restantes son los hombres los que se encuentran buscando trabajo en la actualidad como consecuencia de su 
situación de parados.

Las situaciones laborales descritas para las familias adoptivas se corresponden con las situaciones reales y no ideales aunque ambas coinciden en doce de las veintiuna familias. Ocho familias están llevando a cabo su ideal de trabajar ambos miembros de la pareja fuera del hogar; y cuatro familias lo hacen quedándose uno de los dos miembros en casa. Del total, la mitad de los casos (diez familias) consideran que es más beneficioso para la familia que uno de los dos miembros se quede en casa; para el resto (once casos) esa no es una situación que la pareja desee alcanzar. En el caso de nueve familias no se está llevando a cabo su ideal familiar, ya que siete parejas piensan que es bueno que uno de los dos, hombre o mujer, se quede en casa, pero continúan trabajando los dos, y en los dos últimos casos las mujeres están encargándose exclusivamente de las labores domésticas cuando preferirían, tanto ellas como sus parejas, estar realizando un trabajo remunerado.

Ante el supuesto de tener una situación económica muy buena, cinco familias confirman que seguirían desempeñando sus trabajos del mismo modo que hasta el momento. En otras familias sería la mujer la que dejaría su trabajo y su pareja continuaría con su actividad actual (cinco casos). Hay otras situaciones que imaginan los adoptantes, como que el marido dejara de trabajar y la mujer lo hiciera solo a media jornada (cinco casos); una reducción de jornada para ambos miembros de la pareja (dos casos); que él continuara trabajando mientras ella disfruta de una excedencia (una familia) o que ambos se tomaran excedencias (un caso).

El consenso en el total de familias adoptivas respecto al desempeño de tareas extradomésticas, en el ideal de familia y en los cambios que sufriría su familia ante la llegada de un premio de lotería, recuerda al concepto de "familia negociadora". Dicho término es aplicado al análisis de relaciones intergeneracionales, como la emergencia de un nuevo pacto conyugal caracterizado por la conciliación de intereses y visiones distintas entre los cónyuges (Meil, 2006).

El concepto de familia negociadora no es sinónimo del de "familia simétrica". Ambos emergen en la sociedad postmoderna tras la disolución de la familia patriarcal como consecuencia del proceso de individualización que se produce a lo largo de la segunda mitad del siglo XX. La importancia que adquieren los acuerdos entre ambos miembros de la pareja en el conjunto de familias no se traduce en una distribución equitativa de roles y poder. Existen obstáculos que dificultan la construcción de la pareja en igualdad como la persistente ideología patriarcal y el deficiente desarrollo del Estado de Bienestar español. Por este motivo, hombres y mujeres eligen entre estilos de pareja, negocian aspectos de las relaciones íntimas, pero lo hacen desde diferentes posiciones de género que dificultan la igualdad (Dema y Díaz, 2004).

En este contexto de negociabilidad de las relaciones y de los roles familiares, el reparto de tareas del hogar es muy desigual en beneficio del hombre como ha ocurrido tradicionalmente. La complejidad de medir esta distribución en la pareja es grande; frente al conjunto de tareas que se realizan en el hogar hay al menos tres alternativas (Wainerman, 2005). En este trabajo, se ha seleccionado la proporción de tareas realizadas por cada miembro de la pareja ya que permite efectuar cálculos sobre quién realiza qué aportando una capacidad comparativa entre los porcentajes que asignan cada individuo a su propia actividad y a la de su pareja. El objetivo que se plantea en este apartado de análisis de los relatos es captar la participación de cada miembro, sin implicar la especificidad, evitando el sesgo de la memoria, y la variabilidad del tiempo, que impide la comparativa. Sobre las tareas a indagar se hicieron dos grandes grupos: las tareas del hogar y las de cuidado de los hijos e hijas.

Solo son seis las familias que se reparten el trabajo doméstico de forma equitativa. En los quince casos restantes la mujer tiene una mayor carga de tareas domésticas que su pareja. De 
esas quince familias, son ocho los varones que reconocen que su actividad en el hogar es inferior a la de su esposa. En los otros siete casos los discursos femeninos y masculinos se superponen sin llegar a un acuerdo en el cómputo de tareas que unas y otros realizan; mientras que los hombres tienden a mostrar un equilibrio, las mujeres son las que afirman realizar un mayor número de tareas.

El valor social de la igualdad de los sexos instaurado en la postmodernidad se ha ido incorporando lentamente a la legislación familiar y a la vida cotidiana de las distintas familias. Así, los discursos de las parejas de adoptantes muestran algunos de los avances hacia la paridad entre hombres y mujeres en función de las tareas que realizan o delegan para su organización familiar (Tabla 1).

Tabla 1: Reparto de tareas domésticas por sexo en las familias adoptivas

\begin{tabular}{|l|c|c|}
\hline Actividad $^{\mathbf{1}}$ & Hombre & Mujer \\
\hline Cocinar (comida principal) & 4 & 9 \\
\hline Cocinar (cenas) & 9 & 4 \\
\hline Comprar & 3 & -- \\
\hline Preparar la mesa para comer & 2 & 3 \\
\hline Recoger después de comer & 3 & 3 \\
\hline Fregar los platos y lavavajillas & 2 & 4 \\
\hline Pasar el aspirador & 1 & -- \\
\hline Limpiar el polvo & 1 & 12 \\
\hline Limpiar los baños & -- & 13 \\
\hline Lavar y secar la ropa & 3 & 11 \\
\hline Planchar & 3 & 11 \\
\hline Hacer las camas & -- & 13 \\
\hline Bricolage y arreglos & 1 & -- \\
\hline
\end{tabular}

Fuente: elaboración propia a partir de los relatos cruzados de las familias adoptivas.

Nota 1. Las actividades seleccionadas son las utilizadas en el Proyecto coordinado sobre Redes Familiares en Andalucía del Instituto de Estadística de Andalucía, el Consejo Superior de Investigaciones Científicas y la Universidad Carlos III de Madrid (2003), dirigido por José Antonio Fernández Cordón y Constanza Tobío. Se han omitido dos categorías que hacían referencia a tareas relacionadas con el cuidado de los hijos e hijas y de otras personas dependientes. También se prescindió de la opción "limpiar cristales", ya que no es una actividad que aparezca en los discursos de los adoptantes. Por último, la actividad "limpiar la cocina" se reformula, quedando desglosada en tres actividades: "preparar la mesa", "recoger después de comer" y "fregar los platos/poner lavavajillas". Se añade una actividad más como es el "hacer y cambiar camas".

En la narración de los relatos se les hacía reflexionar a los adoptantes sobre su reparto de tareas en el ámbito doméstico. No existían preguntas específicas para cada uno de las actividades. Las tareas por sexo que se destacan en la Tabla 1, reflejan las especificidades de aquellas familias que han profundizado en la distribución de quehaceres de ámbito doméstico. Tres familias afirmaron que en sus hogares no existen las tareas de hombres y de mujeres, sino que todas son de ambos miembros de la pareja indistintamente. Este contexto define las "tareas neutras" frente a las "tareas femeninas" y "tareas masculinas". Por el contrario, en dos casos es la mujer la que realiza todas las actividades, sin destacar aportación de su pareja, mientras que en otras dos familias solo se considera la ayuda del hombre en el hogar como un hecho puntual. En consecuencia, se puede distinguir una división entre tareas cotidianas y tareas ocasionales, estas últimas mucho más propias del género masculino. Las actividades realizadas por cooperación entre los distintos miembros de la familia (adultos y menores), actividades "neutras", son: la compra, el preparar la mesa, recoger después de 
comer y fregar o poner el lavavajillas.

Pero las tareas no se realizan exclusivamente por los miembros de la pareja, hay otros agentes implicados en la reproducción de la vida cotidiana en sus hogares. La ayuda doméstica asalariada cobra un papel fundamental en la negociación entre los miembros de la pareja: siete casos no tienen una ayuda en casa frente a catorce que sí la tienen. En dos casos no se especifica los días que la persona contratada (en todos los casos mujeres) acude al domicilio pero en el resto de hogares sí que está registrado. Son cuatro los casos que reciben ayuda un día a la semana, cinco solicitan el servicio dos días a la semana y tres casos reciben ayuda doméstica diariamente.

[Entrevistadora: Y, ¿tienes ayuda doméstica?] Pues sí, porque si no estaríamos divorciados (risas).

[Entrevistadora: ¿Cuántos días va a casa?] Todos. Viene todos los días a casa (Madre familia 7, biparental, Moldavia; niñas adoptadas en 2006).

El tiempo dedicado al cuidado de los menores refleja un panorama muy similar al tiempo dedicado a la limpieza del hogar. Doce parejas coinciden a la hora de relatar las tareas de crianza que desempeña cada miembro de la pareja: en seis de los casos el reparto es equitativo, pero en otros seis es la mujer la que comparte más actividades y durante más tiempo con sus hijos e hijas. Nueve parejas no llegan a ponerse de acuerdo en esta asignación: en dos casos el desacuerdo no permite valorar la inversión de esfuerzo y tiempo en la crianza; en otras seis familias, son las mujeres las que manifiestan una mayor implicación por su parte que la que se adjudica a sus parejas; hay un último caso en el que el hombre se valora por debajo de lo que lo ha hecho su mujer. Al igual que para describir el reparto de trabajo doméstico se solicitaron porcentajes del tiempo dedicado a sus hijos e hijas, información que ha permitido realizar las estimaciones anteriores, y emergieron actividades propias de padres y madres con los menores (Tabla 2).

Tabla 2: Actividades de cuidado y crianza de hijos e hijas por sexo

\begin{tabular}{|l|c|c|}
\hline Actividad & Hombre & Mujer \\
\hline Ayudarles en deberes & 3 & 4 \\
\hline Consultas médicas & 1 & 5 \\
\hline Juegos & 3 & 2 \\
\hline Actividades de ocio fuera de casa & 4 & 3 \\
\hline Llevarlos al colegio & -- & 1 \\
\hline Vestirlos & -- & 1 \\
\hline Duchas y aseo & 2 & 1 \\
\hline Dormirlos & 2 & -- \\
\hline
\end{tabular}

Fuente: elaboración propia a partir de los relatos cruzados de las familias adoptivas.

Son muchas las actividades destinadas al cuidado y crianza de los hijos e hijas que se comparten en pareja. En los relatos, pasear, jugar o leer, son actividades que se hacen conjunta o indistintamente por el padre o por la madre. Siguen compartiendo los momentos familiares como los paseos, excursiones y vacaciones, con independencia de la edad de los hijos e hijas. La Tabla 2 destaca aquellos casos en que padres o madres practican actividades exclusivas sin la presencia de su pareja. Independientemente de que exista un reparto en las labores de cuidado, la distribución es más equitativa que en el caso de las tareas del hogar.

Cabe señalar que las tareas de cuidado se delegan a otros agentes en menor medida que las tareas del hogar. Las ayudas por parte de terceros en el cuidado de los menores no suelen ser muy numerosas acudiendo a los centros infantiles y de enseñanza tan pronto como el niño o 
la niña se haya adaptado a la nueva vida familiar. En los casos en los que sí se narra solicitar ayuda para el cuidado de los menores son las abuelas los agentes más destacados; solo en una de las familias se habla de una cuidadora asalariada. La solidaridad intergeneracional, entre familia de orientación y la familia adoptiva, se muestra como un apoyo fundamental en esta sociedad repleta de actividades y carente de tiempo.

Cuando mi hijo era más pequeño, mi madre nos ayudó, ella durante un tiempo sí que se estuvo encargando del niño, de llevarlo a la guardería hasta que fue al cole (Madre familia 3, biparental, Bolivia; niño adoptado en 2002).

Mi marido trabaja fuera ahora. Trabaja en Madrid. Entonces yo dependo total y absolutamente de mis suegros o de los tíos, o de la familia de mi marido porque mi familia no está aquí. Entonces yo termino de trabajar a las tres, soy de esas afortunadas que terminan de trabajar a las tres. Trabajo bastante lejos de mi casa.

Llego a casa, como deprisa y corriendo me voy a por el niño a la guardería y luego, normalmente a las siete, siete y media pues lo dejo en casa de mi suegra y me voy al gimnasio para tener mi hora de liberar tensión del trabajo, de tensión del niño, porque yo de cinco a siete y media ya tengo suficiente (risas). A charrar de otras cosas o a no pensar o lo que sea y eso, normalmente, lo hago de lunes a jueves (Madre familia 9, biparental, Etiopía, niño adoptado en 2009).

La división del trabajo doméstico entre los cónyuges aparece más segregada que las tareas de cuidado de los hijos e hijas más compartidas por ambos miembros de la pareja. Esta distribución de tareas del hogar y de tareas de cuidado está condicionada por el tipo de convivencia que se dé en la familia. Las cuatro mujeres que junto a sus parejas forman familias Living Apart Together (LAT), tienen una clara desventaja respecto al varón. En los cuatro casos es el marido el que viaja y la mujer la que se queda en el domicilio conyugal al cuidado de la casa, de los hijos e hijas y desempeñando un trabajo remunerado (en solo un caso la mujer se queda en casa ya que en la actualidad no tiene trabajo). En algunos de estos casos, la división del trabajo entre los cónyuges cambia en los días laborales y los fines de semana, días festivos o periodos vacacionales.

[Entrevistadora: Estos fines de semana que viene tu marido, ¿compartís actividades los tres?] Sí.

[Entrevistadora: ¿O lo dejas para él?] No. Compartimos, yo los dejo por las mañanas, el hijo es de mi marido, las del sábado y los domingos, y se encarga, bueno cuando Agustín vuelve de entrenar. Lo que te he dicho antes, que vuelve pronto y por las tardes hacemos cosas los dos, los tres quiero decir (Madre familia 9, biparental, Etiopía, niño adoptado en 2009).

Los diecisiete casos restantes conviven juntos pero no por ello deja de existir una mayor carga para la mujer que para el hombre. Hay cuatro mujeres que siguieron los pasos de sus parejas por motivos laborales, lo que les supuso un cambio de residencia, un abandono de su trabajo y un distanciamiento de las familias de orientación.

La mayoría de parejas adoptantes tienen una distribución de roles y poder establecida y consensuada por los años que llevan de convivencia. El tiempo medio es de catorce años y siete meses. Veinte de las familias llevan más de nueve años juntos. Solo, en el caso de la Familia 6, por tratarse de una familia reconstituida, lleva menos años de relación.

Ante el reparto de tareas del hogar y la crianza que se desempeñan en las distintas familias, los discursos femeninos y masculinos muestran aquellas áreas o actividades en las 
que les gustaría una mayor implicación por parte de sus cónyuges para mejorar su dinámica familiar y aumentar su grado de satisfacción. La suma de testimonios de las parejas, apunta que los hombres deberían implicarse más en las tareas del hogar en cuatro casos; en las tareas de cuidado en cinco casos; en cuestiones relacionadas con labores domésticas y de cuidado, en otros cinco casos; y otras implicaciones que se destacan como necesarias por dos familias, sería el disponer de más tiempo o involucrarse en labores humanitarias. Los casos que consideran que en su familia no es necesario que ninguno de los dos miembros de la pareja realice otras actividades (seis casos), son mayoritariamente aquellos hogares en los que existe un reparto equitativo de las tareas del hogar y del cuidado (cuatro de las seis familias).

En el caso de los discursos masculinos, solo un hombre considera que su mujer debería implicarse más, pero no en temas relacionados con el hogar, ni específicos de cuidado, sino en el tipo de actividades que realizan: a él le gustaría realizar más actividades de exterior, "salir más al campo". El resto de varones reconoce el esfuerzo que realizan sus parejas por lo que indican que las mujeres no tienen que aumentar su implicación en ningún aspecto relacionado con la vida familiar. Son los varones los que reconocen que deberían involucrarse más en diferentes actividades (seis casos); en tres casos son ellos lo que perciben la falta de implicación (uno en tareas domésticas, otro en tareas de cuidado y por último, un caso que deben implicarse más en ambas labores). En los tres casos restantes, ambos miembros de la pareja son conscientes de la necesidad del hombre de implicarse en diferentes tareas: en un caso coinciden las opiniones del hombre y la mujer; mientras que en los dos casos restantes se piensa en actividades distintas según el sexo (una pareja en la que ella requiere de una mayor implicación de su marido en tareas de cuidado, mientras que él consideran que su implicación debería ser solo en el hogar; y otra pareja en la que ella demanda una mayor colaboración en las distintas actividades y él considera que su mayor implicación estaría circunscrita a los niños).

El ideal de familia, el reparto de tareas y las demandas para una mayor implicación en el ámbito familiar determinan la unifuncionalidad de los varones. Esta unifuncionalidad se refiere a la figura del hombre dedicada a la esfera pública y al desempeño de su rol en el hogar como padre tradicional. En doce de los casos no se da tal situación pero sí lo manifiestan los nueve casos restantes de uno $\mathrm{u}$ otro modo y en diferentes grados. La unifuncionalidad del varón se reconoce en tres parejas donde existe una división clara entre la esfera pública y la esfera privada atribuidas al hombre y a la mujer respectivamente. En cuatro familias, los diferentes discursos no reconocen dicha división como consecuencia de que existen diferentes tareas pero no diferentes roles (tres de ellos son LAT). Por último, hay dos casos en los que solo los hombres definen como tradicional su dinámica familiar mientras que sus esposas difuminan la división de tareas, eliminando la importancia de una menor implicación masculina.

El trabajo remunerado aporta autonomía y permite la negociación en la pareja. La tenencia de recursos económicos propios ha propiciado la independencia de las mujeres respecto a la figura del varón proveedor. La formación es una de las variables fundamentales en el trabajo a desempeñar. En promedio, los hombres entrevistados tienen una formación inferior a las mujeres.

$\mathrm{Si}$ se recogen todos aquellos atributos (salario, estatus laboral y profesión) que los miembros de la pareja otorgan a los trabajos remunerados dentro de su familia, se obtienen diferencias por sexos. Se pueden distinguir tres modelos de familia, a saber: en el primer modelo es el hombre el que ostenta un mejor trabajo (trece casos); en el segundo, el mejor trabajo lo tienen las mujeres (tres casos); y un tercer modelo que se corresponde con aquellas familias más simétricas en las que ambos miembros tienen trabajos similares (cinco casos). A 
pesar de tener una categoría profesional o tipo de actividad superior, el trabajo femenino pierde valor: los discursos añaden un valor más "exigente" al trabajo de los hombres, en situación de igualdad, por su condición de autónomos, movilidad geográfica o salario.

Esta concepción en la pareja, establece la creencia de que el salario femenino es una ayuda para el hogar no comparable al salario del varón como fuente principal de ingresos. En seis de las familias, los diferentes discursos atribuyen un estatus laboral inferior y se intuye un menor salario aunque, objetivamente, el puesto de trabajo femenino sea igual o superior al masculino. A estos seis casos hay que añadir las cinco familias en las que la mujer en el momento de la entrevista no trabaja fuera del hogar. Los factores institucionales, el sistema económico y las prácticas culturales, permiten, transmiten y favorecen una mejor posición en el mercado laboral a los varones que a las mujeres, lo que tiene un claro reflejo en el ámbito privado (Dema y Díaz, 2004).

En los itinerarios laborales de las mujeres adoptantes aparece un periodo exclusivo dedicado a la crianza de los hijos e hijas que se corresponde con el periodo de baja por maternidad. En todos los casos fueron las mujeres la que tomaron este permiso de dieciséis semanas que, atendiendo a la legislación vigente, puede ser disfrutado por el padre, la madre o de forma conjunta. Solo en dos familias manifiestan que los padres hicieron uso del permiso por paternidad de quince días, principalmente para acudir a los viajes y recoger a sus hijos. En el resto de casos, los hombres hacían uso de las vacaciones para poder constituir la adopción.

En la mayoría de los casos a las familias les pareció suficiente la baja maternal para realizar la adaptación de los menores (dieciséis casos), pero otros dos casos decidieron despedirse de sus empleos y dedicar más tiempo al cuidado y crianza de los menores. Por último, había tres mujeres que en el momento de la adopción no estaban trabajando fuera del hogar por lo que no disfrutaron de ningún permiso, quedándose al cargo de las tareas de cuidado (una mujer por su diagnóstico de invalidez y dos por su situación de desempleo). No es este conteo el que aporta relevancia a la identidad de género, sino aquellos discursos masculinos y femeninos que afirman no haberse planteado otra posibilidad.

[Entrevistadora: ¿Tú crees que si la situación fuera ideal, en el mismo tipo de trabajo, te la seguirías cogiendo tú?] Sí, yo creo que sí.

[Entrevistadora: ¿Por ti o por él, o por los dos?] Por los dos, es que tampoco nos hemos planteado otra cosa. Fíjate si somos simples, no nos hemos planteado otra cosa (risas) (Madre familia 22, biparental, China, niña adoptada en 2006).

El cuidado de los hijos e hijas parece estar todavía asociado más con la mujer que con el hombre. En esa primera etapa es ella la responsable, la encargada de pasar el mayor tiempo con los menores y conseguir su adaptación al entorno familiar. Institucional y socialmente así está planteado, por lo que ante propuestas que se salen de la "norma", como querer coger la baja paternal, se recibe la negativa desde el ámbito laboral debilitando más la igualdad de oportunidades.

[Entrevistadora: Me dijo que tú querías pedirte la baja por paternidad ¿verdad? Pero qué bueno, tuviste que hacer ahí como unos apaños]. Sí, al final vino medio bien porque quería a lo mejor coger un horario a tiempo parcial o alguna cosa así pero vino, justo antes de viajar a China, una carga de trabajo exagerada y, encima, un trabajo que de la oficina solo podía hacerlo yo. Y, entonces, pues llegué un poco a un acuerdo con el jefe. $O$ sea, se fue todo el mundo de vacaciones y yo me quedé allí a hacer horas, incluso a trabajar sábados y domingos, pero bueno, digamos que todo eso me lo fui apuntando y eso. Entonces, me cogí la baja paternal, la de los quince días, 
bueno, en este caso fue dieciocho por el desplazamiento, y luego toda esa... todas esas vacaciones que me quedaban y esas horas que hice de más, me las cogí luego por las tardes, y sí que he estado varios meses sin ir a trabajar por las tardes, y eso ha sido.

[Entrevistadora: Tengo una duda, aunque ella no tenga por qué cogerse la baja de cuatro meses, ¿tú no tienes la opción nunca a cogértela?] Sí, sí.

[Entrevistadora: ¿La de cuatro... dieciséis semanas?] ¿La de las dieciséis semanas? Sí, sí.

[Entrevistadora: Vale, pero ¿la empresa o no te la tomaste porque no considerabas oportuno?]. Yo consideraba que como ella estaba cobrando el paro y esas dieciséis semanas digamos se paralizan el paro y luego sigues, pues, y por no tocar, por no tocar mi trabajo que era la única fuente de ingresos. Pues al final decidimos que mejor que la cogiera ella. Pensamos a lo mejor repartirlo, a lo mejor haber cogido yo una parte y ella otra, pero al final cuadró bien el tema ese de la carga de trabajo de esa y tal, y dijimos venga pues, no, no tocamos nada... y asi en el trabajo no hay problema. Pero sí que es verdad, que en la próxima si llega a buen puerto, sí que me plantearía a lo mejor... Hombre siempre he intentado llegar a un acuerdo con la empresa, a lo mejor no es plan de las dieciséis, porque las dieciséis casi...

[Entrevistadora: ¿Todavía no se ve bien que el hombre se coja...?] No, bueno, en mi empresa ni la mujer, pero bueno (risas), pero sí, el hombre peor. Imagino que si lo llego a hacer, vamos por lo menos de sorpresa le hubiera pillado, pero vamos...

[Entrevistadora: ¿Hubieses sido el primero?] Sí (Madre familia 15, biparental, China, niña adoptada en 2011).

A veces la importancia que tiene el mundo del trabajo para los hombres es tan grande que puede darse el caso de no acudir junto a su esposa a recoger a sus hijos e hijas adoptadas a su país de origen.

Con mi hijo biológico sí, bueno bajas paternales no, los quince días que te daban de eso, pero porque estaba trabajando para una empresa. Con estos dos, con mis hijos adoptivos, no hice nada, como era autónomo no hicimos nada, podía creo que tenía permiso, podría haber solicitado la baja paternal o algo de eso pero tenía que hacer un montón de papeles que...

[Entrevistadora: Y lo dejaste]. Sí. (...) A Etiopia fue mi mujer porque yo no pude ir por el trabajo. Fueron mi mujer y mis dos hijos y una amiga que fue con ella para ayudarla. (...)

[Entrevistadora: Y luego el día a día, tú ya te fuiste a trabajar, me dices que no esos días no pudiste...] Trabajé pero a un ritmo más lento y estuve con ellos, con mi mujer, dijéramos un poco adaptando, adaptando, adaptando la vida a ellos, para que ellos se sintieran mejor, y fue no sé, fue natural todo (Padre familia 10, biparental, Etiopía, niños adoptados en 2009).

La decisión se plantea como un acuerdo entre la pareja, como consecuencia de la situación económica y laboral por la que atraviesa la familia. Una familia en la que la mujer se encarga de la casa y los cuidados y el varón aporta recursos económicos al hogar mediante el trabajo como autónomo en una nueva empresa.

[Entrevistadora: ¿Por qué no pudo ir, no pudo ir a cogerse permiso de paternidad $n i . . . ?]$. No. Él es autónomo y acababa de empezar, entonces eh, teníamos miedo que si nada más empezar pedíamos estos días los poquitos clientes que teníamos se nos fueran a otras y, entonces, decidimos que iba yo sola. (...) 
[Entrevistadora: Cuéntame el encuentro, porque tú bueno viajas sola con los niños ¿no?] Sí.

[Entrevistadora: $Y$ ¿con alguien más?] Con una, la hermana de una amiga, de mi mejor amiga que su madre acababa de fallecer. Ella se lleva también mucho tiempo con su hermana, de edad más o menos andan igual que yo y mi hermana. Y fue como, "llévatela y que se espabile", y yo le dije "me la llevo y que vea alli a la gente". Me la llevé en concepto de canguro, para que me ayudara con los nanos, si no yo no podría, es que no, tú cuéntame en un aeropuerto a las tres de la mañana en Turquía qué hago yo con cuatro nanos, siete, cuatro y tres años, morirme. Entonces yo me la llevé, me la llevé en concepto de canguro, tu enganchas a dos y yo a otros dos (Madre familia 10, biparental, Etiopía, niños adoptados en 2009).

En otros casos en los que los hombres tienen un trabajo autónomo, sus esposas confiesan que durante el tiempo del viaje sus maridos realizaban gestiones laborales. Y, hay otros casos en los que son las mujeres las que fomentan la identificación y disfrute de la crianza con el género femenino ya que afirman que no dejarían que sus maridos cogieran la baja por paternidad.

[Entrevistadora: Aunque la situación hubiese sido los dos funcionarios, ¿tú quién crees que se hubiese cogido la baja?] Yo, yo (risas).

[Entrevistadora: ¿Aunque quisiera no lo habrías dejado?] No, no, ya te digo yo que no (Madre familia 17, biparental, China, niña adoptada en 2008).

Otros argumentos que aparecen en los discursos hacen referencia a sentirse más preparadas que sus parejas para el cuidado de sus menores por considerar la baja un derecho de la mujer o por no querer dejar de disfrutar de esos primeros momentos de su hijo o hija.

\section{CONCLUSIONES}

A modo de conclusión resaltaremos aquellas evidencias obtenidas a partir de los datos obtenidos de los relatos autobiográficos en función de las dos temáticas analizadas en este trabajo. Por un lado, se presenta el proceso de transición como padres y madres de menores adoptados internacionalmente, $\mathrm{y}$, por otro, se sintetizan las pautas fundamentales que se establecen en el seno de las parejas.

El análisis de la paternidad y la maternidad en las familias adoptivas muestra las diferencias en el ejercicio de crianza dependiendo de los miembros de la unidad familiar, de las actitudes y los comportamientos. La maternidad y la paternidad han dejado de tener una única lectura.

Cada caso parece contener particularidades que lo hacen diferente al resto por lo que en una misma familia se pueden vivir paternidades y maternidades distintas. Al igual que sucede en aquellas familias que han constituido más de una adopción, también existen diferencias en la construcción de las maternidades y paternidades en familias de filiación mixta. Las familias constituidas por relaciones diferentes de filiación revelan las peculiaridades de las maternidades y paternidades. Los adoptantes han sido socializados para ejercer una maternidad y una paternidad biológica, por lo que han de desarrollar un abanico de estrategias para adaptarse a las consecuencias de sus elecciones. Los roles de padre y madre son los que se someten a revisión por los adoptantes y, junto a ellos, los mitos sociales sobre la biología y el género. El proceso adoptivo, requisito indispensable para convertirse en 
madre o padre adoptivo, les proporciona las primeras referencias y contactos con el mundo de la adopción.

Con lo que respecta a la división del trabajo doméstico entre los cónyuges, se ha observado que aparece más segregada que las tareas de cuidado de los hijos e hijas, más compartidas por ambos miembros de la pareja. Esta distribución de tareas del hogar y de tareas de cuidado está condicionada por el tipo de convivencia que se da en la familia.

Por tanto, se puede aseverar que las mujeres de la muestra transitan por tres modelos de itinerarios laborales: el modelo tradicional, el modelo secuencial y el modelo simultáneo (Meil, 1999). En el modelo tradicional solo se da en un caso y por cuestiones ajenas a la voluntad personal y grupal, sino por condiciones de salud; la madre solo trabaja antes de tener a su primer hijo (hijo biológico). El modelo secuencial se lleva a cabo por siete mujeres. Este modelo se refiere al grupo de madres que interrumpen su actividad laboral cuando sus hijas e hijos son pequeños y lo retoman cuando el menor entra en el colegio o en aquellos otros casos donde las mujeres han solicitado una reducción de jornada laboral. En este último caso, con reducción de jornada, se encuentran dos mujeres, una ha recuperado el trabajo y cuatro mujeres tras tener a sus hijas e hijos continúan en casa en situación de desempleo, aunque reconocen que les gustaría volver al mercado laboral. En último lugar y abarcando la mayoría de familias (trece casos), las mujeres desempeñan un modelo simultáneo ya que tras la baja maternal no han interrumpido su actividad laboral en ningún otro momento del ciclo vital.

Los resultados de la muestra evidencian que a pesar de los cambios introducidos en la configuración de su estructura familiar, continúan manteniendo las persistencias en la distribución de los roles en función del género.

\section{BIBLIOGRAFÍA}

Ayuso, L. (2007) Las asociaciones familiares en España. Madrid: Centro de Investigaciones Sociológicas.

Beck, U. y Beck-Gernsheim, E. (2003) La individualización: el individualismo institucionalizado y sus consecuencias sociales y políticas. Barcelona: Paidós Ibérica.

Cea D'Ancona, M. A. (2007) La deriva del cambio familiar: hacia formas de convivencia más abiertas y democráticas. Madrid: Centro de Investigaciones Sociológicas.

Dema, S. y Díaz, C. (2004) "La construcción de la igualdad en las parejas jóvenes: de los deseos a las prácticas cotidianas". Revista de Estudios de la Juventud, 67: 101- 113.

Denzin, N. K. (1989) Interpretive biography. Newbury Park: Sage.

Instituto Nacional de Estadística (2016) Estadística de Medidas de Protección a la Infancia: Adopciones, Acogimientos y Tutela de Menores, en www.ine.es [consulta 30/07/2018].

Jareño-Ruiz, D. (2014) Familias en transición: estudio sociológico de las familias adoptivas internacionales en la provincia de Alicante (tesis doctoral). Alicante: Universidad de Alicante.

Lesthaeghe, R. (1995) "The second demographic transition in Western countries: An interpretation", en K. Oppenheim y A. Jensen (Eds.) Gender and family change in industrialized countries. New York: Oxford University Press, pp. 17-62.

Meil, G. (2006) Padres e hijos en la España actual. Barcelona: Fundación La Caixa.

Meil, G. (1999) La postmodernización de la familia española. Madrid: Acento.

Miall, C. E. (1989) "Reproductive technology vs. the stigma of involuntary childlessness". Social Casework, 70 (1): 43-50.

Patton, Michael Q. (1990) Qualitative evaluation and research methods. Newbury Park: Sage.

Rodríguez-Jaume, M.J. y Jareño-Ruiz, D. (2015) "Estigma social y adopción internacional en España: ¿es la familia adoptiva un modelo familiar menos "auténtico" que los basados en lazos biológicos?" 
Papers: Revista de Sociología, 100 (2): 211-236.

Selman, P. (2012) "Tendencias globales en adopción internacional: ¿en el 'interés superior de la infancia'?" Scripta Nova. Revista Electrónica de Geografía y Ciencias Sociales, XVI, 395 (21), en http://www.ub.edu/geocrit/sn/sn-395/sn-395-21.htm [consulta 30/07/2018].

Selman, P. (2006) "Trends in intercountry adoption: Analysis of data from 20 receiving countries, 1998-2004". Journal of Population Research, 23 (2): 183-204.

Valles, M. (1997) Técnicas cualitativas de investigación social: reflexión metodológica y práctica profesional. Madrid: Síntesis.

Van de Kaa, D. J. (1987) "Europe's second demographic transition". Population Bulletin, 42 (1), 1-59.

Wainerman, C. (2005) La vida cotidiana en las nuevas familias: ¿una revolución estancada? Buenos Aires: Lumiere.

Weston, K. (2003) Las familias que elegimos: lesbianas, gays y parentesco. Barcelona: Bellaterra.

\section{Breve currículo:}

\section{Diana Jareño Ruiz}

Licenciada (Premio Extraordinario de Promoción 2002-2006) y Doctora en Sociología (Doctorado con Mención Internacional, 2014) por la Universidad de Alicante (UA). Es Profesora Ayudante Doctora en el Departamento de Sociología I de la UA. Actualmente, es investigadora del Proyecto Nacional I+D+i "Un nuevo escenario para la infancia: actitudes, motivaciones y disponibilidad de la población española hacia la adopción y el acogimiento", y de otros proyectos de ámbito europeo y autonómico. Su colaboración en grupos de investigación, sus contribuciones a congresos y sus diferentes publicaciones, se enmarcan dentro de las áreas de familia, población, migraciones, género y educación. 